\title{
LA EVOLUCIÓN DE LAS PAUTAS DE CONSUMO DE LAS FAMILIAS VALENCIANAS. UNA APROXIMACIÓN A LOS CAMBIOS DE COMPORTAMIENTO EN EL SIGLO XVIII*
}

\author{
The Evolution of the Consumption Patterns \\ of the Valencian Families. An Approximation to the Changes \\ of Behavior in the 18th Century
}

\author{
Luis Miguel ROSADO CALATAYUD \\ Universidad de Valencia \\ luis.rosado@uv.es
}

Fecha de recepción: 25/11/2018

Fecha de aceptación definitiva: 10/01/2019

RESUMEN: En las áreas más dinámicas de la Europa Occidental la llamada revolución del consumo hizo su aparición a finales del XVII. También en la España Mediterránea se produjeron cambios significativos en las pautas adquisitivas de las familias, derivados del excepcional desarrollo económico experimentado a lo largo del siglo XVIII. Cambios que dudamos en calificar de revolucionarios -ya que responden a un proceso progresivo en el que intervienen múltiples variables-, y que en nuestra opinión consideramos que el término que mejor caracteriza este período es el de evolución del consumo. La base documental utilizada en este estudio comparativo la constituye un conjunto de escrituras de dote repartidas entre el medio rural y el urbano. Y la atención se ha centrado en el vestido, que, además de ser el artículo con mayor representación en este tipo de documentos, es el mejor ejemplo como indicador del consumo familiar (Veblen dixit).

* El presente trabajo se inserta en el marco del proyecto «Nuevas perspectivas de historia social en los territorios hispánicos del Mediterráneo occidental en la Edad Moderna» (HAR2014-53298-C2-1), financiado por el Ministerio de Economía y Competitividad. 
Palabras clave: consumo; cultura material; moda; indumentaria; economía familiar; siglo XVIII.

ABSTRACT: In the most dynamic areas of Western Europe the so-called revolution of the consumption did his appearance at the end of the seventeenth century. Also in Mediterranean Spain significant changes took place in the acquisitive guidelines of the families, derivatives of the exceptional economic development experienced along the 18th century. Changes that we doubt to qualify of revolutionaries, since they respond to a progressive process in which multiple variables intervene, and that in our opinion we consider that the term that best characterizes this period is the evolution of consumption. The documentary base used in this comparative study is a set of dowry deeds distributed between rural and urban areas. And the attention has been focused on the dress, which besides being the article with the highest representation in this type of documents, is the best example as an indicator of family consumption (Veblen dixit).

Key words: consumption; material culture; fashion; clothing; family economy; eighteenth century.

\section{A MODO DE INTRODUCCIÓN}

La atención por la historia social del consumo, que surge como corriente de investigación en las últimas décadas del siglo xx, ha venido mostrando un interés creciente por las transformaciones que las sociedades del Antiguo Régimen experimentaron en los hábitos adquisitivos, derivados de los cambios de comportamiento de la demanda, como consecuencia de las relaciones de mercado, y la consiguiente evolución de las estructuras productivas. Como señala Ramón Maruri «se trataba de un giro en la mirada del historiador, que desplazaba hacia la demanda el protagonismo en el proceso industrializador, motor del crecimiento económico moderno» ${ }^{1}$. Neil McKendrick acuñó el término consumer revolution ${ }^{2}$, y lo relacionó directamente con la "revolución industrial». Esta decisiva transformación de los hábitos adquisitivos habría hecho su aparición en las áreas más dinámicas de Europa Occidental a finales del XVII. También, en la España mediterránea, como tendremos ocasión de comprobar, se produjeron cambios significativos derivados del excepcional desarrollo económico experimentado a lo largo del siglo XVIII.

Este estudio pretende conocer si estas mismas transformaciones en las pautas de consumo aparecieron antes en el medio urbano que en el rural, y en qué

1. Maruri Villanueva, Ramón. "La Historia Social del Consumo en la España Moderna: un estado de la cuestión”. Estudis. Revista de Historia Moderna, 2016, 42, pp. 267-301.

2. MCKENDRICK, Neil. «The consumer Revolution of Eighteenth-Century England». En McKeNDRICK, N.; BREWER, J. y PLUMB, J. H. The birth of a consumer society. The commercialization of EighteenthCentury England. London-Bloomington: Europa Publications Limited, 1982, pp. 9-33. 
medida llegó a ser determinante no solo el lugar de residencia, sino también los niveles económicos, culturales, profesionales y sociales de las familias.

Para poder obtener las evidencias sobre la cambiante realidad que presenta la cultura material hemos recurrido al análisis de más de un millar de documentos notariales. En concreto se han estudiado las "cartas dotales», y entre los diferentes bienes que aparecen en este tipo de escrituras, de un modo especial, nos hemos detenido en los productos textiles. La ropa de casa y la indumentaria personal son objeto de atención en el 99\% de este tipo de documentación. Las "cartas matrimoniales", además de proporcionarnos información sobre el valor de tasación de los distintos tipos de prendas, nos ofrecen detalle de los tejidos utilizados para su confección, de su composición, su estado de uso, así como de los colores, los adornos y complementos.

La amplia muestra de protocolos notariales seleccionados está referida a diferentes poblaciones del área central del territorio valenciano. Una zona geográfica que experimentó en el Setecientos un gran dinamismo en sus economías, nacido de la expansión de la agricultura de carácter intensivo, arropada por un eficiente sistema de regadío. Como resultado de lo anterior la capacidad adquisitiva de las familias fue evolucionando, lo que posibilitó superar los niveles de subsistencia. También en estas latitudes podemos hablar de nuevas pautas adquisitivas en las familias valencianas, aunque con una cronología diferente a la de otras zonas europeas.

Los cambios que en materia de consumo incorporaron los habitantes de estas poblaciones no pueden calificarse de revolucionarios, ya que responden a un proceso progresivo, en el que intervienen una amplia pluralidad de variables. En este sentido, consideramos que el término que mejor caracteriza este período es el de evolución del consumo.

\section{EL MEDIO Y SUS PROTAGONISTAS}

El territorio valenciano a lo largo del siglo XVIII fue escenario de una importante serie de transformaciones en todos los órdenes. La intensificación de la producción y la especialización de los cultivos, derivada de las enormes posibilidades que ofrecía la exportación, consiguieron que la agricultura se modernizara y, al calor de la misma, se produjo un importante incremento demográfico ${ }^{3}$. El protagonismo en el crecimiento de la agricultura comercial y la difusión de las relaciones de mercado en la Valencia del siglo XVIII hay que otorgarlo a la morera y al cultivo del arroz.

La amplia zona que comprende las comarcas de las dos Riberas del Xùquer y la Costera, repartidas entre el litoral y el interior valenciano, tenían como actividad principal, aunque con un desigual peso, la producción agraria. Esta parte del territorio valenciano constituye un claro ejemplo de las modalidades de crecimiento

3. ARDit LuCAS, Manuel. "Los estudios sobre historia agraria del País Valenciano en la edad Moderna". Noticiario de Historia Agraria: Boletín del Seminario de Historia Agraria, 1991, 2, pp. 95-102. 
agrario intensivo y extensivo, que tiene como protagonistas el binomio moreraarroz, los dos cultivos hegemónicos, pero con un distinto desarrollo cronológico.

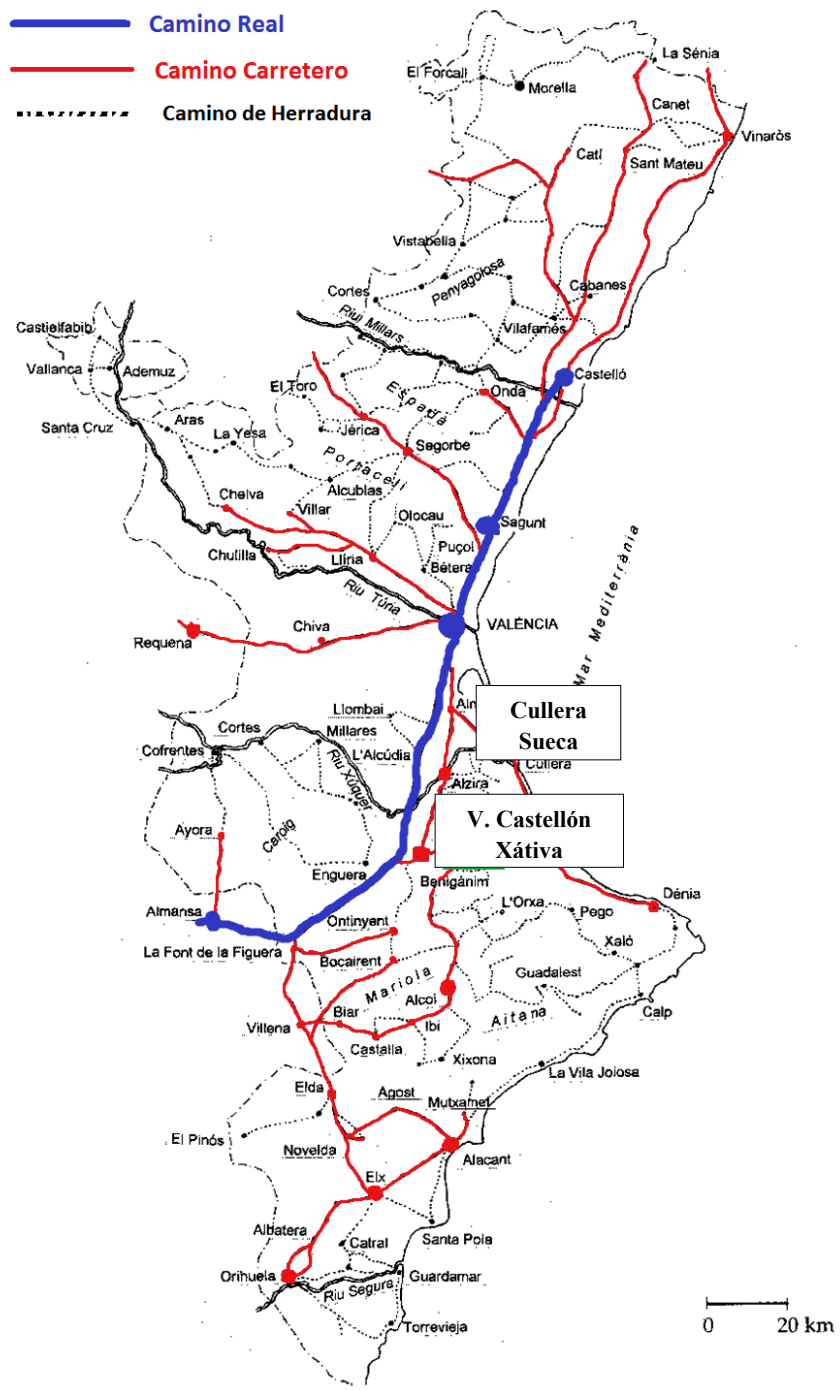

UBICACIÓN DE CULLERA, SUECA, VILLANUEVA DE CASTELLÓN Y XÀTIVA EN LA RED DE CAMINOS SEGÚN EL MAPA GEOGRÁFICO DEL REYNO DE VALENCIA DE DE A. J. CAVANILLES 1795.

Fuente: SANCHIS Deusa, C. "Els camins valencians de la segona meitat del segle XVIII i les Observaciones de Cavanilles». Cuadernos de Geografía, 1997, n. ${ }^{\circ} 62$, pp. 455-483. 
Las referidas comarcas mantenían las características propias de una sociedad rural, en la que la base de su economía estaba sustentada, de manera casi exclusiva, por la agricultura. La débil presencia de la industria -limitada en la práctica al entorno de la ciudad de Xàtiva $-^{4}$ no se debe entender como sinónimo de sociedad retardataria.

Desde el siglo XVI el desarrollo de la producción agraria venía determinado por su marcado carácter extensivo: roturación de tierras incultas, forestales y baldías, desecación de pantanos, zonas de marjal. De manera progresiva esta modalidad de crecimiento tradicional fue adquiriendo una mayor utilidad. La principal novedad que nos ofrece el siglo XVIII responde a la adopción de métodos intensivos de cultivo, lo que convierte el esfuerzo realizado en más eficaz. Hay que destacar la creciente difusión de los sistemas de roturación cada vez más complejos, que posibilitaban la supresión del barbecho, así como el incremento en el número de cosechas; lo que permitía cultivar distintos productos. En el Setecientos, junto a los estándares tradicionales las modalidades de expansión incidieron en la diversificación de la producción agraria, la especialización regional y la intensificación 5 .

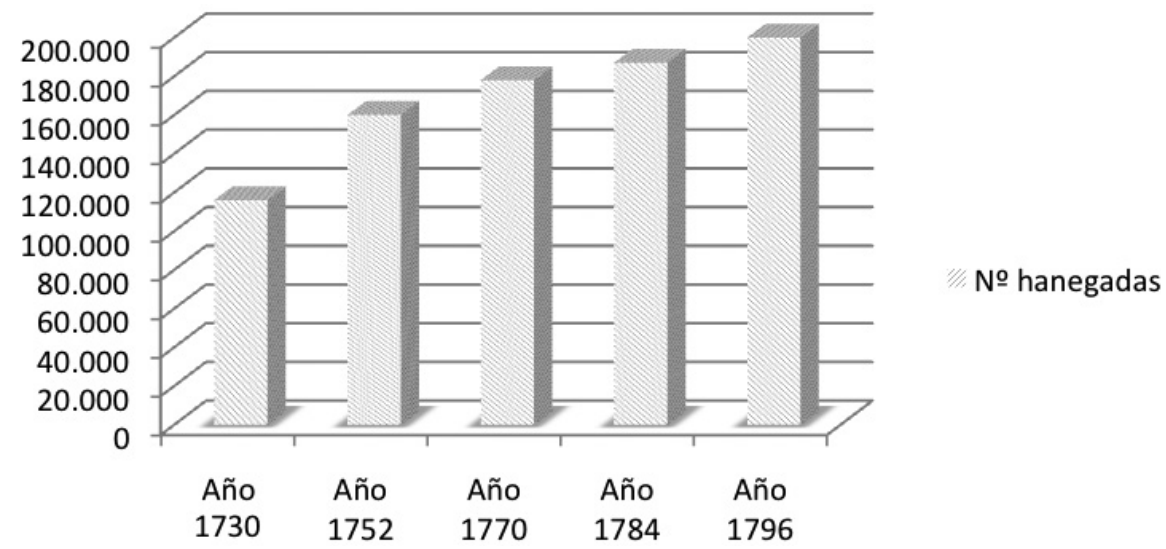

Gráfico 1. Evolución de la superficie destinada al cultivo de arroz en Valencia. Elaboración propia. Fuente: E. MATEU TORTOSA ${ }^{6}$.

La extensión del regadío posibilitó la integración de cereales de invierno y de primavera, pero además permitió que en los márgenes de las parcelas se

4. Sobre la evolución de la manufactura de Xàtiva véase: RIBES IBORRA, Vicente. La industrializació de la zona de Xàtiva en el context valencià (1710-1910). Xàtiva: Ayuntamiento de Xàtiva, 1994.

5. ARDit LuCAS, Manuel. «La Historia Rural de la España Oriental durante la Edad Moderna: Un estado de la cuestión». Studia Historica. Historia Moderna, 2007, n. ${ }^{\circ}$ 29, pp. 47-82.

6. Mateu Tortosa, Enric. Arroz y paludismo. Riqueza y conflictos en la sociedad valenciana del siglo XVIII. Valencia: Alfons el Magnànim, 1987, p. 50. 
cultivaran plantas arbóreas y arbustivas ${ }^{7}$. La intensificación resultó mucho más beneficiosa para la producción agrícola que la ampliación de las tierras de cultivo ${ }^{8}$.

Sin abandonar la tradicional tríada mediterránea, se habían venido incorporando nuevos cultivos con una clara orientación comercial. En primer lugar, se optó por la morera, producto con una importante demanda como consecuencia de la sericicultura, actividad en auge en la ciudad de Valencia durante buena parte de la Edad Moderna9. Si bien, fue la introducción del cultivo del arroz lo que provocaría una desigual cronología en el crecimiento de la economía de estas dos comarcas $^{10}$.

Derivado de la expansión de la agricultura, se incentivó un importante flujo migratorio, que desde diferentes puntos de la península buscaba mejores oportunidades en tierras valencianas, lo que se tradujo en un incremento demográfico muy considerable ${ }^{11}$, con una mayor incidencia a los años centrales del Setecientos $^{12}$. Este período viene a coincidir con una etapa de cambios estructurales, que conllevaron una ruptura con las tradicionales formas de autosubsistencia ${ }^{13}$. Lo anterior confirió a estas áreas una mayor orientación de la economía doméstica hacia el mercado y la conformación dentro de la sociedad de prácticas diferentes en sus hábitos de compra que afectaron a todos los estratos sociales. Estos espacios territoriales, aunque comparten una multiplicidad de elementos comunes, que constituyen la base de sus economías, presentan singularidades en lo que a las pautas de consumo se refiere. Actitudes diferentes que determinan la actuación de los sujetos derivadas del nivel adquisitivo; la posición social y profesional; e incluso la repercusión que ofrece el lugar de residencia, dependiendo de que este sea de carácter urbano o rural, o de las particulares formas de sociabilidad a las que responde un determinado segmento de la población, solo por enumerar

7. ARDit LuCAS, Manuel. Els homes i la terra del País Valencià (segles XVI-XVIII). Barcelona: Curial, 1993, vol. II, p. 69.

8. PÉRIS Albentosa, Tomás. «El objetivo de equidad y el criterio de proporcionalidad en las instituciones hidráulicas valencianas (siglos XVI-XIX)». Investigaciones Geográficas, 2017, 67, pp. 101-121.

9. Franch BenAVENT, Ricardo. La sedería valenciana y el reformismo borbónico. Valencia: I. Alfons el Magnànim, 2000, pp. 15-22.

10. PÉREZ GARCía, José M. "Los orígenes de la moderna agricultura comercial en la Huerta de Valencia (1700-1850)». En El medio rural español. Cultura, paisaje y naturaleza. Homenaje a Ángel Cabo Alonso. Salamanca: Universidad de Salamanca, 1994, vol. I, pp. 475-498.

11. Rosado Calatayud, Luis M. "Sociedad, cultura material y consumo textil en el medio rural valenciano a lo largo del siglo XVIII. El caso de Sueca». Estudis. Revista de Historia Moderna, 2010, 36, pp. 259-278.

12. Franch Benavent, Ricardo. «Dimensiones económicas del Setecientos español: Los distintos modelos de crecimiento». En Martínez Ruiz, E. y De PAzZis PI Corrales, M. (eds.). Ilustración, ciencia y técnica en el siglo XVIII español. València: Universitat de València, 2008, pp. 183-207.

13. Matoses Cuquerella, Rafael. "L'Establiment de terres a Sueca. La Qüestió social de l'ocupació de l'erm al segle XVIII". Quaderns de Sueca, 1984, V, pp. 55-77. Véase también AZAGRA, J.; MATEU, E. y VIDAL, J. (eds.). De la Sociedad tradicional a la Economía moderna. Estudios de Historia Valenciana Contemporánea. Alicante: Diputación-Instituto de Cultura Juan Gil Albert, 1996, pp. 101-124. 
algunas de ellas. Todos estos condicionantes se traducen en comportamientos adquisitivos disímiles ${ }^{14}$.

\section{LOS ARTÍCULOS TEXTILES COMO REFERENTE DE LA CULTURA MATERIAL}

En la disposición de los bienes que aparecen en las escrituras de dote, los elementos que componen los ajuares de las futuras esposas son los más numerosos, aunque no son los de mayor peso económico, como se puede comprobar en el Gráfico 2. La ropa de casa y, de manera especial, la indumentaria personal, son los artículos que nos ofrecen una excelente información sobre los comportamientos seguidos por las familias valencianas en materia de consumo.

La función que adquiere el vestido, por encima de la de preservar el cuerpo, es la de tratar de ofrecer hacia el exterior una imagen de la situación económica de la persona que lo posee. El gasto realizado en el vestido se hace pensando en la imagen que proporciona, más que en la protección de la persona. Como muy bien señala Thorsthein Veblen «Ninguna especie de consumo presenta un ejemplo mejor que el gasto realizado en materia de vestido» ${ }^{15}$.

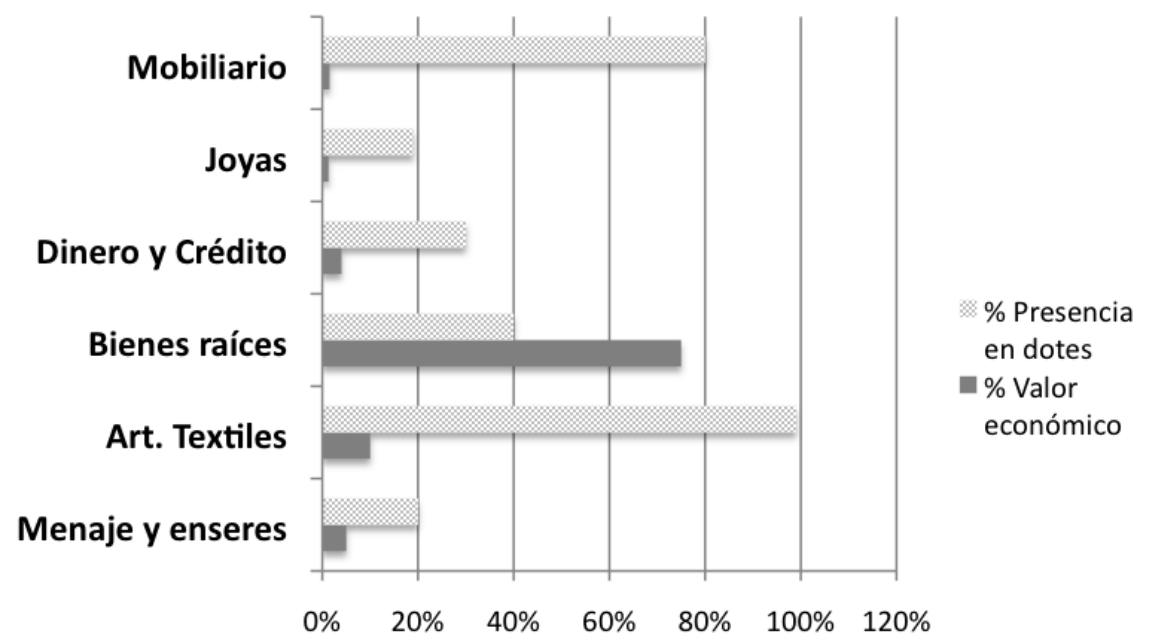

Gráfico 2. Distribución en \% de los tipos de bienes que contienen las cartas dotales. Elaboración propia. Fuente: Protocolos notariales poblaciones de la Ribera Alta y Baja y La Costera.

14. Rosado Calatayud, Luis M. Consum familiar en la societat preindustrial valenciana. Contrastos entre el medi rural i l'urbà. (Sueca-Xàtiva. 1700-1824). Valencia: Institució Alfons el Magnànim, 2017, pp. 222-284.

15. VeBlen, Thorstein. Teoría de la clase ociosa. México: Fondo de Cultura Económica, 1992, p. 160. 
Además de lo expuesto, entre los diferentes tipos de productos que aparecen en las cartas dotales, consideramos que los textiles son los elementos más característicos. Aunque no concentran los valores más elevados -cuyo protagonismo corresponde a los bienes raíces: los inmuebles y las tierras de cultivo, reservados para las donaciones de las familias más adineradas-, están presentes en la práctica totalidad de esta clase de documentos, y su incidencia económica es la segunda en orden de importancia.

Partimos de una muestra próxima a las 600 escrituras repartida entre media docena de poblaciones, aunque las más significativas corresponden a Cullera, Sueca, Villanueva de Castellón y la ciudad de Xàtiva. Toda esta documentación nos permite disponer de información de cerca de 20.000 prendas de indumentaria y de ajuar doméstico, con el detalle de los tipos de fibra, los colores, los adornos utilizados, el valor de tasación e incluso, en ocasiones, su estado de conservación.

Para la reconstrucción de los patrimonios familiares y la evolución de sus rentas, hemos recurrido también a información de tipo económico y fiscal, como son los Libros del Equivalente y los Padrones de Riqueza.

\section{PROGRESIÓN DEL VALOR ECONÓMICO DE LAS DOTES EN EL SIGLO XVIII}

Hemos distribuido las dotes siguiendo el criterio de categorización por intervalos del valor de tasación de las dotes, que es el que ha utilizado Rosa Congost ${ }^{16}$. La clasificación comprende desde los niveles inferiores a las 50 libras valencianas -equivalente a 753 reales de vellón ${ }^{17}$, que era la cantidad mínima necesaria para constituir una dote y que era la que destinaban fundaciones y entidades benéficas a dotar a "Doncellas huérfanas" 18 . Esta cantidad se puede considerar el umbral de referencia para las "clases pobres». Siguiendo de forma escalonada vamos ascendiendo por los niveles intermedios hasta llegar a las consideradas como "clases ricas», aquellas familias que dotaban a sus hijas con cantidades situadas por encima de las 1.000 libras, en torno a los 15.000 reales de vellón.

A nivel global, podemos observar en el Cuadro n. ${ }^{\circ} 1$ cómo las cantidades que destinan las familias experimentan un notable crecimiento, en consonancia con la mejor situación de los niveles de renta. Conviene precisar que la muestra resulta

16. Congost Colomer, Rosa. "Els dots com a indicadors de les desigualtats socials i la seva evolució en el temps». En Ros Massana, Rosa (ed.). Els capítols matrimonials. Una Font per a la Història Social. Girona: Biblioteca d'Història Rural, 2010, pp. 162-193.

17. Una libra valenciana equivale a 15 reales y 2 maravedís de vellón.

18. A título de ejemplo destacamos la iniciativa de la Real Sociedad Económica de Amigos del País de Valencia, puesta en marcha en 1777, o la de la Fundación Juan Rubert, que se remonta a 1614, en ambos casos destinaban anualmente cantidades para dotar a "Doncellas pobres huérfanas". Circular de 10 de septiembre de 1777 al Arzobispado para adjudicar dotes ofrecidas en 20 de agosto del mismo año... C.2, Año 1777, Leg. I. https://riunet.upv.es/handle/10251/18484/discover. Archivo Histórico Municipal de Sueca (en adelante AHMS). Administración Rubert. Caixa 115. Plens Municipals. Ref. 1.02 .06 sec. 6. Año 1752-1761, Libro único. 1753, fols. 126r.-127v. 
muy representativa ya que abarca desde las familias menos favorecidas hasta las mejor situadas económicamente.

\begin{tabular}{|c|r|r|r|r|}
\hline $\begin{array}{c}\text { INTERVALOS DE TASACIÓN } \\
\text { EN LIBRAS }\end{array}$ & $\mathbf{1 7 0 0 / 1 7 2 5}$ & $\mathbf{1 7 2 6 / 1 7 5 0}$ & $\mathbf{1 7 5 1 / 1 7 7 5}$ & $\mathbf{1 7 7 6 / 1 8 0 0}$ \\
\hline Menos de 50 & 15,79 & 13,46 & 7,84 & 1,06 \\
\hline De 50 a 100 & 34,21 & 29,49 & 26,14 & 19,15 \\
\hline De 101 a 200 & 25,00 & 29,49 & 24,18 & 41,49 \\
\hline De 201 a 500 & 14,47 & 15,38 & 24,84 & 21,28 \\
\hline De 501 a 1.000 & 3,95 & 6,41 & 8,50 & 7,45 \\
\hline Más de 1.000 & 6,58 & 5,77 & 8,50 & 9,57 \\
\hline Total dotes & 100,00 & 100,00 & 100,00 & 100,00 \\
\hline
\end{tabular}

Cuadro 1. Distribución (\%) de las dotes según los importes de tasación (1700-1800). Elaboración propia. Fuente: Protocolos notariales poblaciones de la Ribera Alta y Baja y La Costera.

No obstante, esta situación no resulta homogénea para las diferentes poblaciones ${ }^{19}$. Si nos atenemos exclusivamente a los artículos textiles, aquellos que conforman el ajuar de las novias, propiamente dicho, el comportamiento no sigue las mismas pautas. Podemos afirmar que, mientras que la evolución que experimentan las cantidades destinadas a la dote está estrechamente relacionada con la situación de la economía en general, en el caso de las ropas de casa y la indumentaria personal, además de las condiciones económicas, inciden otra serie de factores. Es de esos de los que nos vamos a ocupar a continuación.

\section{FACTORES QUE INCIDEN EN LOS CAMBIOS DE COMPORTAMIENTO FRENTE AL CONSUMO}

Como hemos señalado, aunque las bases del crecimiento agrario valenciano hay que situarlas en la segunda mitad del Seiscientos, un siglo después se producen importantes trasformaciones en el área geográfica objeto de este estudio. La intensificación de la producción y la especialización en determinados cultivos, aquellos que ofrecían mayores rendimientos, comportó un proceso modernizador de la agricultura. La disponibilidad de excedentes permitía que estos se destinaran a su comercialización, tanto al mercado interno peninsular como a la exportación hacia el exterior.

19. Los niveles de partida eran más elevados en casos como el de Villanueva de Castellón -localidad que había experimentado un fuerte crecimiento a inicios del siglo XVIII-, en la segunda mitad del Setecientos se produjo un importante cambio de tendencia. A partir de 1750 las dotes de poblaciones como Cullera o Sueca ofrecían unos niveles económicos muy superiores al resto. En el caso de Xàtiva se producía esta misma tendencia en el último cuarto de siglo. 
Una de las consecuencias de esta situación expansiva fue la creciente necesidad de mano de obra, que, de un lado, se solucionó mediante la llegada de nuevos pobladores y, de otro, con la participación en los procesos productivos de un mayor número de miembros de la unidad familiar ${ }^{20}$.

No obstante, la cronología y las peculiaridades que ofrece su desarrollo en cada una de las poblaciones que nos sirven de muestra resultan muy diferentes. Aunque todas ellas tienen en la agricultura el motor de sus economías, debemos distinguir entre las poblaciones de la comarca de La Costera, dentro de la Ribera del Xùquer, la división entre las zonas altas y bajas, con tierras muy distintas en lo que a las condiciones edafológicas se refiere ${ }^{21}$.

La promulgación por Fernando VI de la Real Orden fechada el 14 de abril de 1753 -mediante la cual se delimitaban, de un modo muy minucioso, las zonas donde se permitía la siembra y aquellas donde quedaba totalmente prohibido el cultivo de los arroces- tuvo desiguales consecuencias para las dos áreas. Para garantizar su cumplimiento, se determinó la participación de las autoridades locales. Este decreto -conocido como el "Acotamiento de arroces» ${ }^{22}$ favoreció a las poblaciones de la Ribera Baja, mientras que perjudicó económicamente a las situadas en las comarcas de La Costera, así como a determinadas poblaciones de la Ribera Alta del Xúquer, que perderían como consecuencia de esta delimitación hasta el $45,5 \%$ de la superficie destinada a arrozal. La excepción la constituye la ciudad de Xàtiva, que, aunque se sitúa en la zona afectada por la restricción del cultivo, vio limitada la incidencia en su economía de esta prohibición, por varias razones. De un lado, por apostar por el cultivo de la morera, pero sobre todo por su producción artesanal, y de manera especial por su actividad comercial. Xàtiva de facto era la capital económica del suroeste de la actual provincia de Valencia y la zona norte de la provincia de Alicante. En la práctica su binterland se extendía a más de un centenar de poblaciones, así como un amplio número de aldeas, repartidas en 53 municipios. A mediados del siglo XVIII -cuando consiguió recuperarse de la destrucción padecida en 1707 derivada de la guerra de Sucesión-23 ocupaba el cuarto lugar, por número de habitantes, del Reino de Valencia. Su privilegiada localización a la entrada de dos valles y en el cruce de dos importantes vías de penetración hacia el interior de la península le confería una situación estratégica para las comunicaciones.

20. De VRIES, Jan. La Revolución Industriosa. Consumo y Economía domestica desde 1650 hasta el presente. Barcelona: Critica, 2009, pp.105-107.

21. Constituyen los dos ejemplos de la división que, respondiendo a criterios sanitarios relacionados con la propagación del paludismo, realizó el botánico Cavanilles, quien diferenciaba los tipos de suelo entre "terrenos naturalmente pantanosos y terrenos artificialmente pantanosos". CAVANILLES, A. J. "Observaciones sobre el cultivo del arroz en el Reyno de Valencia y su influencia en la salud pública». En Memorias de la Real Academia Médica de Madrid. Madrid: Imprenta Real, 1797, Tomo Primero, pp. 99-128.

22. AHMS, Acotamiento de arroces, Exp. S.P.1, Caja 1, 1753-1793.

23. Véase Ramírez Aledón, G. y Blesa Duet, I. La destrucció de Xàtiva en 1707 i el govern de la ciutat en l'exili. Xàtiva: Ulleye, 2007. 
Contrariamente, en las poblaciones próximas al lago de la Albufera se produjo un formidable incremento de las zonas donde el cultivo estaba permitido ${ }^{24}$. El arroz pasó a tener la condición de monocultivo, lo que obligó al vecindario a tener que proveerse del resto de los artículos necesarios, lo que, unido al incremento de la renta familiar, generó un considerable cambio de las relaciones de mercado.

La aparición de nuevas necesidades de la población acabaría generando un incremento de la demanda, cada vez más numerosa y variada, lo que obligó a ajustar la oferta para cubrir las nuevas exigencias. De un lado, existía un mayor flujo de disponibilidad económica en las familias, pero también se empezó a producir lo que Veblen señala como consumo derrochador, mediante el cual las personas se privaban de algunas comodidades y cosas necesarias, con objeto de poderse permitir la adquisición de determinados tipos de artículos ${ }^{25}$, al menos en lo que a la composición de las dotes se refiere.

Los cambios en el comportamiento en materia adquisitiva seguidos por las familias también alcanzaron al hábitat doméstico. El orden y la distribución de los espacios interiores experimentaron trasformaciones importantes en el transcurso del siglo XVIII. El mobiliario adquirió una mayor profusión. Las sillas, mesas, armarios, vitrinas, cómodas y escritorios fueron ocupando espacios destacados en los domicilios de los vecinos con mayor poder adquisitivo, o de aquellos que buscaban una mayor proyección social, ya que las viviendas conquistaron una dimensión pública. Las cortinas, espejos, cuadros, así como los diferentes elementos de decoración, pasaron a conquistar una mayor significación.

\section{El VESTIDO COMO INDICADOR DEL CONSUMO}

Hemos hecho referencia a una de las acepciones que el Diccionario de la Real Academia de la Lengua Española muestra para el vocablo vestido, que guarda relación con la protección del cuerpo, pero así mismo lo define como "cualquier adorno o adición que se pone para hermosear alguna cosa o encubrir la realidad ${ }^{26}$. Según esta segunda significación, mediante la utilización de determinados tipos de prenda, las personas pretenden mejorar su aspecto o, incluso, disimular algún defecto o carencia. En definitiva, proyectar hacia el exterior una imagen diferente. Con el vestido se trata de expresar, identificar y dar a conocer a la persona que lo posee ${ }^{27}$. En este sentido, el vestido se convierte en una forma

24. Franch Benavent, Ricardo. «La intervención de la Junta de Comercio de Valencia en la política arrocera de la monarquía en la segunda mitad del siglo XVIII: Los informes emitidos sobre la naturaleza de las tierras de la Ribera del Xúquer». Revista de Historia Moderna, 2005, 23, pp. 391-414.

25. VeBlen, Thorstein. Teoría..., op. cit., p. 87.

26. http://ntlle.rae.es/ntlle/SrvltGUILoginNtlle, RAE 1780, p. 925.

27. García Fernández, Máximo. «El vestido y la moda en la Castilla moderna. Examen simbólico». Vínculos de Historia, 2017, 6, pp. 135-162. 
de comunicación social ${ }^{28}$. Cuestiones como el lugar de residencia y el perfil socioprofesional de las personas generan unas diferentes necesidades en lo que se refiere al aspecto exterior ${ }^{29}$.

Queremos destacar que a medida que las dotes alcanzan los niveles más elevados de tasación disminuye el peso de los artículos textiles sobre el total de bienes, ya que en las mismas aparecen otro tipo de recursos como joyas, efectos personales, dinero efectivo, bienes raíces o mobiliario. Con carácter general, las dotes con niveles de valoración económica más elevadas disponen de un abanico de opciones, tanto en indumentaria, como en el ajuar doméstico, mucho más diverso.

\begin{tabular}{|c|c|c|c|c|c|c|c|c|}
\hline \multirow[b]{2}{*}{$\begin{array}{l}\text { INTERVALOS DE } \\
\text { TASACIÓN EN LIBRAS }\end{array}$} & \multicolumn{2}{|c|}{$1700 / 1725$} & \multicolumn{2}{|c|}{$1726 / 1750$} & \multicolumn{2}{|c|}{$1751 / 1775$} & \multicolumn{2}{|c|}{$1776 / 1800$} \\
\hline & 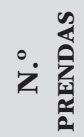 & 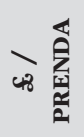 & 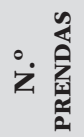 & 旅 & 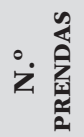 & 妵 & 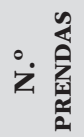 & $>\underset{1}{4}$ \\
\hline Menos de 50 & 27,7 & 1,26 & 25,2 & 1,25 & 20,0 & 1,30 & 23,5 & 1,40 \\
\hline De 50 a 100 & 34,5 & 1,55 & 35,7 & 1,56 & 37,5 & 1,56 & 38,4 & 1,70 \\
\hline De 101 a 200 & 43,5 & 2,09 & 43,8 & 1,64 & 51,5 & 2,07 & 50,1 & 2,27 \\
\hline De 201 a 500 & 48,6 & 2,11 & 50,9 & 1,79 & 52,3 & 2,42 & 62,9 & 2,43 \\
\hline De 501 a 1.000 & 49,7 & 2,48 & 61,7 & 1,98 & 68,6 & 2,41 & 60,4 & 3,09 \\
\hline Más de 1.000 & 68,5 & 2,22 & 63,7 & 2,85 & 80,5 & 2,91 & 83,2 & 4,11 \\
\hline Media total & 42,3 & 1,89 & 43,5 & 1,79 & 49,5 & 2,20 & 54,3 & 2,57 \\
\hline
\end{tabular}

Cuadro 2. Número y valor medio de las prendas de indumentaria. (Según los intervalos de tasación de las dotes en libras). Elaboración propia. Fuente: Protocolos notariales poblaciones de la Ribera Alta y Baja y La Costera.

No obstante, según recoge el Cuadro n. ${ }^{\circ} 2$, no siempre se produce una relación directa entre el nivel económico de las familias y el valor de tasación de las prendas que componen las dotes. Como ya hemos señalado, además de las cuestiones económicas, intervienen diferentes factores a la hora de conformar la composición de las dotes. Las familias pueden llegar incluso a endeudarse para conseguir un matrimonio favorable a sus intereses ${ }^{30}$.

28. ECO, Umberto. "El hábito hace al monje». En Psicología del Vestir. Barcelona: Lumen, 1976, pp. 7-23.

29. Roche, Daniel. La culture des apparences. Une bistoire du vêtement XVII-XVIII siècle. Paris: Fayard, 1991, p. 27.

30. Se levantaron diferentes voces que criticaban «los excesos en los vestidos y las modas...". Ver Sempere Guarinos, Juan. Historia del Luxo y de las leyes suntuarias de España. Madrid: Imprenta Real, 1788, p. 153. 
LA EVOLUCIÓN DE LAS PAUTAS DE CONSUMO DE LAS FAMILIAS VALENCIANAS EN EL SIGLO XVIII

\begin{tabular}{|c|c|c|c|c|c|c|c|c|}
\hline \multirow[b]{2}{*}{$\begin{array}{l}\text { INTERVALOS DE } \\
\text { TASACIÓN EN LIBRAS }\end{array}$} & \multicolumn{2}{|c|}{$1700 / 1725$} & \multicolumn{2}{|c|}{$1726 / 1750$} & \multicolumn{2}{|c|}{$1751 / 1775$} & \multicolumn{2}{|c|}{$1776 / 1800$} \\
\hline & $\dot{0} \sum_{\substack{n \\
\frac{n}{n}}}^{\sum_{n}^{n}}$ & 》九 & 这 & ४ & 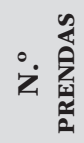 & 》望 & 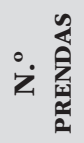 & ৬旅 \\
\hline Jornaleros & 33,9 & 1,48 & 33,0 & 1,58 & 32,1 & 1,56 & 37,4 & 1,74 \\
\hline Labradores & 44,6 & 1,49 & 43,2 & 1,87 & 56,4 & 2,39 & 51,0 & 2,65 \\
\hline Artesanos & 34,8 & 2,08 & 40,6 & 1,56 & 50,2 & 1,77 & 57,2 & 2,43 \\
\hline Prof. liberales & 66,8 & 2,45 & 66,8 & 2,51 & 58,3 & 2,91 & 78,0 & 2,86 \\
\hline Comerciantes & 44,0 & 3,23 & 42,6 & 2,89 & 62,0 & 2,41 & 50,0 & 2,58 \\
\hline Hacendados & 46,4 & 2,24 & 34,5 & 2,71 & 83,0 & 3,10 & 77,1 & 4,70 \\
\hline Otros & 42,2 & 1,73 & 46,1 & 1,71 & 42,9 & 1,91 & 52,5 & 2,43 \\
\hline Media total & 42,3 & 1,89 & 43,5 & 1,79 & 49,5 & 2,20 & 54,3 & 2,57 \\
\hline
\end{tabular}

Cuadro 3. Número y valor medio de las prendas de indumentaria de las dotes (Según la actividad socioprofesional de las familias) ${ }^{31}$. Elaboración propia. Fuente: Protocolos notariales poblaciones de la Ribera Alta y Baja y La Costera.

Como se pude apreciar en el Cuadro 3, en las escrituras correspondientes a las hijas de los hacendados, aquellos campesinos con mayores niveles de renta, podemos localizar las prendas con tasaciones más elevadas, algunas de ellas confeccionadas con tejidos de importación. Además, en su mayoría, se trata de artículos de reciente adquisición. Frente a las anteriores, en las escrituras de los niveles económicos inferiores, el lienzo casero, y con posterioridad el algodón, son los más utilizados. Es en este nivel de clasificación donde las prendas usadas, e incluso viejas, son las más numerosas ${ }^{32}$. El mercado de ocasión es muy importante y, en cierta medida, contribuye a una transmisión vertical de la moda ${ }^{33}$.

31. En este apartado hemos incluido aquellos documentos en los que no se indica la profesión de la persona que constituye la dote. En ocho de cada diez casos como toda referencia únicamente aparece: "viuda" $\mathrm{y}$ "doncella», se trata de cartas dotales otorgadas por las propias mujeres, bien a favor de sus hijas o con motivo de sus segundas nupcias.

32. Fernando Ramos indica que la ropa usada está presente de manera abundante en el ámbito rural. Entre las posibles causas señala «el menor poder adquisitivo de la población campesina, el menor grado de apertura hacia el mercado, los mayores costes de transacción y de organización de las redes comerciales, debido a la dispersión de la demanda, e incluso no descarta explicaciones de tipo sociológico y cultural». Ramos Palencia, Fernando. Pautas de consumo y mercado en Castilla 1750-1850. Economía familiar en Palencia al final del Antiguo Régimen. Madrid: Sílex, 2010, p. 126.

33. MCCRACKEN, Grant D. "Consumer Goods, Gender Construction, and a Rehabilitated TrickleDown Theory». En Culture and consumption: New approaches to the symbolic character of consumer goods and activities. Bloomington: Indiana University Press, 1988, pp. 93-103. 
Por lo que se refiere a las dotes constituidas por aquellas familias que destinan una parte del capital económico a capital social, cultural o simbólico, como son las de comerciantes y las de aquellos vecinos que ejercen profesiones liberales, por lo general, son las primeras en incorporar las innovaciones, además de disponer de un mayor número de prendas. Por último, hay que señalar que en el 44,77\% de los casos no disponemos de información relativa a la actividad profesional que desempeñan las personas que suscriben las escrituras, son los que se recogen en el apartado «otros». En este grupo, tanto el número de prendas como el valor medio de las mismas se sitúa en valores ligeramente inferiores a los de los totales.

\begin{tabular}{|c|c|c|c|c|c|c|c|c|}
\hline \multirow[b]{2}{*}{$\begin{array}{l}\text { INTERVALOS DE } \\
\text { TASACIÓN EN LIBRAS } \\
\text { MEDIO RURAL }\end{array}$} & \multicolumn{2}{|c|}{$1700 / 1725$} & \multicolumn{2}{|c|}{$1726 / 1750$} & \multicolumn{2}{|c|}{$1751 / 1775$} & \multicolumn{2}{|c|}{$1776 / 1800$} \\
\hline & 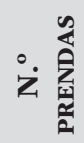 & 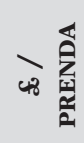 & 运 & 旅 & 远 & \冬 & 运 & 就 \\
\hline Menos de 50 & 35,1 & 1,13 & 23,0 & 1,28 & 33,3 & 1,18 & 23,0 & 1,11 \\
\hline De 50 a 100 & 32,3 & 1,31 & 34,7 & 1,43 & 40,5 & 1,63 & 37,3 & 1,68 \\
\hline De 101 a 200 & 40,9 & 2,11 & 43,5 & 1,46 & 51,5 & 2,07 & 48,1 & 2,34 \\
\hline De 201 a 500 & 56,3 & 1,71 & 47,7 & 2,05 & 53,8 & 2,35 & 57,1 & 2,55 \\
\hline De 501 a 1.000 & 87,0 & 2,18 & 39,7 & 2,18 & 68,6 & 2,41 & 58,8 & 3,14 \\
\hline Más de 1.000 & 57,0 & 2,63 & - & - & 84,3 & 2,79 & 84,4 & 3,87 \\
\hline Media total & $\mathbf{4 0 , 3}$ & 1,49 & 40,6 & 1,64 & 46,2 & 1,94 & 53,7 & 2,27 \\
\hline
\end{tabular}

Cuadro 4. Número y valor medio de las prendas de indumentaria de las dotes. Poblaciones del medio rural. (Según los intervalos de tasación en libras valencianas). Elaboración propia. Fuente: Protocolos notariales poblaciones de la Ribera Alta y Baja y La Costera.

En las decisiones de compra de las familias hacia determinados productos, además de la disponibilidad económica, influyen de forma destacable los factores sociales y culturales. Los estilos de vida vienen determinados de manera especial por el grado de instrucción y la pertenencia a un determinado grupo socioprofesional. Sus componentes son objeto de imitación por aquellos que pretenden acceder a estos grupos sociales. Hemos podido observar que se producen determinados comportamientos miméticos de las familias respecto a los grupos que conforman las élites culturales y sociales $^{34}$.

34. Rosado Calatayud, Luis M. «Moda, la sociabilidad y nuevos patrones de consumo en el reino de Valencia en el siglo XVIII. El caso de la ciudad de Xàtiva». Estudis. Revista de Historia Moderna, 2016, 42, pp. 155-176. 
Por otra parte, podemos apreciar por los Cuadros 4 y 5 como en las dotes correspondientes a las poblaciones del medio rural -a excepción de algunos valores más elevados, que pueden obedecer a los diferentes criterios de tasación utilizados- tanto el número medio de piezas como los importes por prenda resultan ligeramente inferiores a los de las dotes constituidas por los habitantes de la ciudad de Xàtiva. En relación con esta última, en las dotes con valores de tasación superior a las 1.000 libras, podemos observar un elevado número de prendas en las primeras décadas del siglo. Se trata de dotes que contienen una amplia variedad de artículos, aunque algunos de valor reducido -como pañuelos, medias, peinadores, guantes, ligas, corbatas y otros complementos, entre los que hay que incluir los zapatos-, que resulta muy superior a la media ${ }^{35}$. Por el contrario, en el último cuarto de siglo debido a la incidencia de una sola dote, la correspondiente a María Ximeno y Puig, aunque el número de prendas es más reducido, el valor medio de las mismas resulta especialmente elevado ${ }^{36}$.

Por lo que se refiere a los diferentes tipos de prenda, si a inicios del siglo XVIII eran frecuentes las basquiñas, generalmente de color negro -algunas destinadas exclusivamente para "ir a misa" ${ }^{37}$, como aparecen en la documentación- con el transcurso de los años se produce un incremento en la variedad de colores utilizados. También en tierras valencianas se adopta una moda en el vestir mas colorida y reluciente, como señala Daniel Roche, dejando atrás unas prácticas bastante adustas $^{38}$. En las casacas, los guardapiés y los vestidos, se utilizaba preferentemente la seda ${ }^{39}$. Fibra que, por sus dibujos y colorido, resultaba muy apreciada para la confección de los vestidos de señora.

35. Archivo del Reino de Valencia (en adelante ARV). Protocolos Bartolomé Trobat, Sig. 8070, año 1724, fols. 133r.-142r.; Sig. 8060, año 1720, fols. 16r.-19v.; Sig. 8072, año 1727, fols. 86r.-89r.; Sig. 8073, año 1729, fols. 106v.-112v.

36. Archivo Histórico Municipal de Xàtiva (en adelante AHMX). Protocolos de J. Gascó, Sig. LB-1426, año 1784, fols. 198v.-205v. Se trata de la dote de D. ${ }^{a}$ María Vicenta Ximeno Tejedor Judici de Acharte, hija de D. Pedro Ximeno Puig de Samper y García de Padilla, regidor y contador de las rentas de Propios y Arbitrios de Xàtiva y de D. ${ }^{a}$ María Vicenta Tejedor Judici de Acharte. Entre las diferentes prendas de vestir que se recogen en esta dote podemos localizar cuatro batas (gasa, espolín, seda y plata) valoradas en conjunto en 410 libras. ROSADO CALATAYUD, Luis M. "El vestido y el ajuar doméstico: Evolución de las pautas de consumo del textil en el medio rural valenciano a lo largo del siglo XVIII". En MuÑoz NAVARRO, Daniel (ed.). Comprar, Vender y Consumir. Nuevas aportaciones a la historia del consumo en la España Moderna. Valencia: PUV, Universitat de València, 2011, pp. 173-197.

37. ARV. Protocolos de Basilio Berenguer, Sig. 13.970, año 1703, s/fol. (dote Vicenta Burgos); Sig. 13.971, año 1704, s/fol. (dote Isabel Juan Baldoví); Sig. 13.972, año 1705, s/fol. (dote María Beltrán), s/fol. (dote Andrea Sisteró), y Protocolos de Jerónimo Beltrán, Sig. 12.666, año 1730, fols. 1r.-3r. (dote Ana María Rebull).

38. Roche, Daniel. "Between a "Moral Economy" and a "Consumer Economy". Clothes and Their Function in the 17th and 18 th Centuries". En Fox, Robert y Turner, Anthony (eds.). Luxury Trades and Consumerism in Ancien Régime Paris. Studies in the History of the Skilled Workforce. Ashagate: Aldershot (Hamoshire), 1998, p. 223.

39. Descalzo Lorenzo, Amalia. "Vestirse a la moda en la España Moderna». Vínculos de Historia, 2017, 6, pp. 105-134. 
En las dos últimas décadas del siglo, las prendas de indumentaria que aparecen en las dotes tienen un valor muy inferior, salvo las excepciones comentadas, debido a la irrupción del algodón, "ese favorito de la moda ${ }^{40}$. La utilización de los tejidos de algodón, gracias a su colorido, fue un poderoso acelerador del consumo. Personificaron el cambio en la concepción de la moda en el vestido, que hasta entonces estaba dominado por matices oscuros. La prenda que mejor protagoniza esta transformación es el "zagalejo de indiana " ${ }^{41}$, falda que vendría a desplazar al guardapiés, que era resistente "y podían pasar de generación en generación» ${ }^{42}$. La elevada presencia de los zagalejos en las dotes constituidas por cualquiera de los niveles económicos responde a su reducido valor de tasación, lo que provocaría una disminución de los importes destinados al vestido.

\begin{tabular}{|c|c|c|c|c|c|c|c|c|}
\hline \multirow[b]{2}{*}{$\begin{array}{l}\text { INTERVALOS DE } \\
\text { TASACIÓN EN LIBRAS } \\
\text { MEDIO URBANO }\end{array}$} & \multicolumn{2}{|c|}{$1700 / 1725$} & \multicolumn{2}{|c|}{$1726 / 1750$} & \multicolumn{2}{|c|}{$1751 / 1775$} & \multicolumn{2}{|c|}{$1776 / 1800$} \\
\hline & 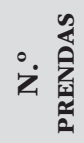 & $>\frac{\widehat{Z}}{4}$ & 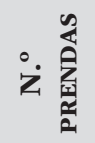 & \旅 & 远 & 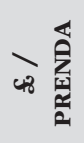 & 安后章 & 就 \\
\hline Menos de 50 & 20,0 & 1,92 & 27,7 & 1,14 & 32,3 & 1,40 & - & - \\
\hline De 50 a 100 & 33,8 & 1,79 & 40,8 & 1,55 & 36,4 & 1,64 & 31,7 & 2,14 \\
\hline De 101 a 200 & 43,3 & 2,14 & 49,4 & 1,69 & 55,0 & 2,37 & 63,6 & 1,73 \\
\hline De 201 a 500 & 36,0 & 3,09 & 42,0 & 1,16 & 41,0 & 2,14 & 109,0 & 1,57 \\
\hline De 501 a 1.000 & 25,0 & 1,44 & 99,0 & 2,81 & - & - & 80,0 & 2,59 \\
\hline Más de 1.000 & 161,0 & 1,69 & 132,0 & 3,67 & - & - & 64,0 & 9,54 \\
\hline Media total & 44,2 & 1,91 & 61,0 & $\mathbf{1 , 8 0}$ & 35,1 & $\mathbf{1 , 8 1}$ & 61,2 & 2,42 \\
\hline
\end{tabular}

Cuadro 5. Número de prendas de indumentaria y valor medio por intervalos de tasación. Ciudad de Xàtiva. Elaboración propia. Fuente: Protocolos notariales poblaciones de la Ribera Alta y Baja y La Costera.

40. De VRIES, Jan. La Revolución Industriosa..., op. cit., pp. 166-169.

41. La indiana era un tejido de algodón con ligamento tafetán y su característica principal era el estampado mediante planchas de cobre o madera entintada, que, sobre un fondo blanco, mostraba rayas y dibujos sencillos, generalmente a un color. Mónica Miquel Piera señala la presencia de este tejido en toda clase de pañuelos, así como en vestidos y jubones. En nuestro caso lo hemos encontrado de manera prácticamente exclusiva en los zagalejos. RuIz OrTEGA, Manuel. La Escuela Gratuita de Diseño de Barcelona, 1775-1808. Barcelona: Biblioteca de Catalunya, 1999, pp. 90-102. PIERA MiQUEL, Mónica. "Els usos de les indianes a la Barcelona del segle XviII: decorar la llar o vestir la gent?». En SÁNCHEZ, A. (coord.). La industria de les indianes a Barcelona, 1730-1850. Barcelona: Ajuntament de Barcelona, 2011, pp. 67-84.

42. Lemire, Beverly. "Second-hand Baux and "Red-armed Belles". Conflict and the Creation of Fashions in England, c. 1660-1800». Continuity and Change, 2000, 15, p. 395. 
Desde las familias mejor situadas económicamente hasta las más humildes. Las faldas que responden a esta denominación comienzan a aparecer hacia 1770. La primera la hemos localizado en Cullera, lo que indica la influencia que tiene el puerto como vehículo de entrada de la moda. Algo más de una década después las podemos encontrar en las dotes de Sueca ${ }^{43}$, y un año más tarde en las de Villanueva de Castellón ${ }^{44}$. Por su parte, en la ciudad de Xàtiva no se ha localizado ninguna dote que contenga zagalejos de indiana hasta el año $1784^{45}$, sin embargo, a partir de ese momento proliferaron de manera notable en todas las dotes, con independencia de las cantidades que las familias destinaban al vestido.

\section{LAS CARTAS DOTALES CON NIVELES DE VALORACIÓN EXTREMOS}

Para aproximarnos con mayor detalle al comportamiento de la evolución del consumo, hemos querido centrar la atención en dos variedades de fibras: la seda y el algodón ${ }^{46}$. La primera debido a su consideración de artículo de lujo y la segunda por su carácter innovador ya comentado. Se ha seleccionado una representación de las dotes, que viene a suponer prácticamente la quinta parte de la documentación total ${ }^{47}$. Intencionadamente se ha prescindido de los niveles intermedios con el objetivo de hacer más visibles los contrates en materia de consumo. La selección realizada nos ofrece una imagen socioprofesional muy representativa de la total, tanto para el medio rural como para el urbano. Un elevado número de labradores y hacendados, en el primer caso, y una mayor presencia de menestrales y profesiones liberales, en el segundo, componen este grupo escogido.

En los niveles de tasación inferiores, el tipo de prendas que más proliferan en las dotes corresponden a aquellas en las que en su composición intervienen fibras derivadas del «lienzo casero" - lino y cáñamo-, y con posterioridad el algodón, aunque la seda y la lana puedan estar presentes, como podemos comprobar.

Las prendas textiles correspondientes a las dotes del área urbana mantienen hasta el último cuarto de siglo una evolución muy similar en valoración y en número. Por lo que al vestido se refiere, se produce un ligero crecimiento en el número de prendas, aunque el valor se mantiene constante, incluso se reduce. En los últimos 25 años del siglo llega a duplicarse, tanto el número de las prendas como los importes, respecto a los períodos anteriores. El peso del textil

43. ARV. Protocolos de Marcos Aparicio Jr., Sig. 12.463, año 1782, fols. 61v.-63v.

44. Archivo Histórico de Villanueva de Castellón (en adelante AHVC). Protocolos de Pedro Juan Franco, Sig. 1319-1334, año 1783, s/fol.

45. AHMX. Protocolos de J. Gascó, Sig. LB-1426, año 1784, fols. 92r.-95r.

46. Rosado Calatayud, Luis M. "Entre sedas y algodones. La evolución del ajuar en la dote de las novias a lo largo del siglo XVIII". Estudis. Revista de Historia Moderna, 2011, n. ${ }^{\circ}$ 37, pp. $429-446$.

47. Se han elegido cuarenta dotes por cada población, distribuidas en los cuatro apartados en que hemos dividido cronológicamente el siglo en períodos de 25 años. En esta selección únicamente se han tomado las dotes situadas en los valores extremos de tasación, cinco para los inferiores y otras tantas para los superiores. 
constituye, como media a lo largo de todo el siglo, el 90\% del total del valor de los bienes donados. Las prendas de indumentaria personal son las que tienen una mayor incidencia en conjunto de la dote, ya que representan algo más del $70 \%$ del valor de las prendas textiles. Los artículos de seda tienen presencia desigual en las dotes con niveles de valoración inferiores, con una incidencia creciente a lo largo del siglo, en total sintonía con el comportamiento global ya comentado. En la segunda mitad del siglo este tipo de tejidos llegó a constituir un tercio del total del textil, con un distinto reparto entre el ajuar doméstico y la indumentaria. Los datos en detalle se pueden evidenciar en los cuadros siguientes.

\begin{tabular}{|c|c|c|c|c|c|}
\hline \multicolumn{2}{|r|}{ CONCEPTOS } & $1700-1725$ & $1726-1750$ & 1751-1775 & $1776-1800$ \\
\hline \multirow{5}{*}{ 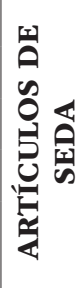 } & Valor prendas seda & 7,30 & 8,30 & 10,90 & 22,90 \\
\hline & N. ${ }^{\circ}$ prendas seda & 3,00 & 3,00 & 4,00 & 4,80 \\
\hline & Valor medio prendas seda & 2,43 & 2,77 & 2,73 & 4,77 \\
\hline & $\%$ Valor seda/total textil & $18,30 \%$ & $24,20 \%$ & $33,00 \%$ & $34,40 \%$ \\
\hline & $\begin{array}{l}\% \text { n. }{ }^{\circ} \text { prendas seda } / \mathrm{n} .{ }^{\circ} \\
\text { total prendas }\end{array}$ & $16,00 \%$ & $12,80 \%$ & $17,10 \%$ & $15,70 \%$ \\
\hline \multirow{5}{*}{ 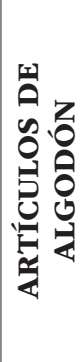 } & Valor prendas algodón & - & - & 0,80 & 4,20 \\
\hline & N.․ prendas algodón & - & - & 0,60 & 2,40 \\
\hline & $\begin{array}{l}\text { Valor medio prendas } \\
\text { algodón }\end{array}$ & - & - & 1,33 & 1,75 \\
\hline & $\begin{array}{l}\text { \% Valor algodón/total } \\
\text { textil }\end{array}$ & - & - & $2,40 \%$ & $6,30 \%$ \\
\hline & $\begin{array}{l}\% \text { n. }{ }^{\circ} \text { prendas algodón } / \text { n. }^{\circ} \\
\text { t. prendas }\end{array}$ & - & - & $2,60 \%$ & $7,80 \%$ \\
\hline
\end{tabular}

Cuadro 6. Artículos de seda y algodón. Área urbana. Selección de cartas dotales con valor de tasación inferior. Elaboración propia. Fuente: Protocolos notariales poblaciones de la Ribera Alta y Baja y La Costera. 
LUIS MIGUEL ROSADO CALATAYUD

LA EVOLUCIÓN DE LAS PAUTAS DE CONSUMO DE LAS FAMILIAS VALENCIANAS EN EL SIGLO XVIII

\begin{tabular}{|c|c|c|c|c|c|}
\hline \multicolumn{2}{|r|}{ CONCEPTOS } & 1700-1725 & 1726-1750 & 1751-1775 & $1776-1800$ \\
\hline \multirow{5}{*}{ 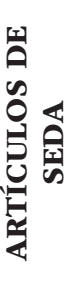 } & Valor prendas seda & 7,90 & 11,10 & 12,90 & 16,10 \\
\hline & N. ${ }^{\circ}$ prendas seda & 2,20 & 3,80 & 3,40 & 3,60 \\
\hline & Valor medio prendas seda & 3,59 & 2,92 & 3,79 & 4,47 \\
\hline & $\%$ Valor seda/total textil & $19,60 \%$ & $36,40 \%$ & $31,10 \%$ & $41,60 \%$ \\
\hline & $\begin{array}{l}\% \mathrm{n}^{\circ} \text { prendas seda } / \mathrm{n} .{ }^{\circ} \\
\text { total prendas }\end{array}$ & $6,10 \%$ & $17,60 \%$ & $11,00 \%$ & $12,50 \%$ \\
\hline \multirow{5}{*}{ 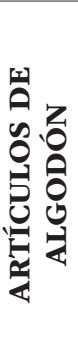 } & Valor prendas algodón & - & 1,40 & 5,50 & 2,60 \\
\hline & N. ${ }^{\circ}$ prendas algodón & - & 0,60 & 4,40 & 2,60 \\
\hline & $\begin{array}{l}\text { Valor medio prendas } \\
\text { algodón }\end{array}$ & - & 2,33 & 1,25 & 1,00 \\
\hline & $\begin{array}{l}\text { \% Valor algodón/total } \\
\text { textil }\end{array}$ & - & $4,60 \%$ & $13,30 \%$ & $6,70 \%$ \\
\hline & $\begin{array}{l}\% \text { n. }{ }^{\circ} \text { prendas algodón } / \mathrm{n}^{\circ} \\
\text { t. prendas }\end{array}$ & - & $2,80 \%$ & $14,30 \%$ & $9,00 \%$ \\
\hline
\end{tabular}

Cuadro 7. Artículos de seda y algodón. Área rural. Selección de cartas dotales con valor de tasación inferior. Elaboración propia. Fuente: Protocolos notariales poblaciones de la Ribera Alta y Baja y La Costera.

En la ciudad, incluso en las dotes con niveles de valoración más bajos, la presencia de las ropas de seda es importante. Es habitual que en las dotes aparezcan más de un guardapiés, más de un delantal y más de un jubón, además de medias, pañuelos y mantillas, por lo que a la indumentaria de las futuras novias se refiere. En cuanto al ajuar doméstico, también podemos destacar una mayor presencia de cobertores y antecamas de seda, que en el de las dotes del medio rural. La ausencia de artículos de algodón es total en los primeros cincuenta años del siglo. En la segunda mitad, especialmente en el último cuarto de siglo, se produce la llegada de indianas, concretamente zagalejos confeccionados con este tipo de tejido, además de pañuelos, delantales, mantillas, en muselina. Por lo que al ajuar se refiere, podemos localizar alguna colcha de cotona ${ }^{48}$. La aparición del algodón no se produce hasta 1752 y con una incidencia muy reducida, tan solo se han localizado tres prendas confeccionadas con esta fibra para este período. En el último cuarto de siglo llega a tener cierta significación en el número de prendas de indumentaria $(11,1 \%)$

En las dotes de este nivel correspondientes al medio rural, el valor de los artículos textiles y, de modo especial, el referido a las prendas de indumentaria se 54r. $-56 \mathrm{v}$

48. La primera aparece en 1752. ARV. Protocolos de José Cervera, Sig. 3.067, año 1752, fols. 
mantiene constante a lo largo de todo el siglo; únicamente entre 1726 y 1750 se produce un descenso en el número y en el valor de las ropas de casa, que condiciona el total. La seda, a partir del segundo cuarto de siglo, consigue duplicar el número de prendas y se mantiene en un nivel constante. En el caso de la indumentaria representa un tercio del total. Su valoración se incrementa de modo progresivo en los años siguientes, llegando a significar un 53\% al final del siglo XVIII.

Aunque inicialmente la incidencia de los tejidos de algodón en conjunto es muy baja, entre 1751 y 1775 prácticamente un tercio de las prendas de indumentaria que aparecen en las dotes están confeccionadas con este tipo de fibra. La explicación está en la aparición a partir de 1761 de camisas de "Lienzo de Francia» y "Lienzo Naval», con precios que oscilan entre 1 y 2 libras. Si bien, esta situación no se repite en el último cuarto de siglo y la presencia de las prendas de vestir de algodón se limita al 12\%, siendo menor incluso la incidencia en las ropas de casa.

El tipo de prendas de vestir confeccionadas con fibras de seda es muy similar tanto en el medio rural como en el urbano: guardapiés, delantales, jubones y, en menor medida, las mantillas. No obstante, el número de artículos es inferior en número al que se registra en la ciudad de Xàtiva.

Las prendas que tienen como materia prima las diferentes variedades de algodón empezarán a aparecer en las dotes a partir de la segunda mitad del siglo. Además de las camisas, a las que nos hemos referido, encontramos enaguas, y algunos jubones y delantales. En cuanto a la ropa de cama, los cobertores y antecamas, cuando aparecen, suelen ser de seda, mientras que las fundas de las almohadas son de algodón. El resto de los artículos de ajuar doméstico tiene el lino como materia prima.

En resumen, las telas de seda que encontramos en las dotes con niveles inferiores de valoración, tanto en el medio rural como en el urbano, suelen ser aldúcar, hiladillo, musulmana, riza y tafetán ${ }^{49}$. En menor medida aparecen las sedas de mejor calidad como la nobleza, el terciopelo o el damasco, y cuando lo hacen se trata de piezas usadas. El algodón comienza a adquirir cierta importancia, aunque de manera muy lenta.

Por lo que respecta a las dotes de los niveles de valoración superior (Cuadros 8 y 9), las constituidas por los vecinos con rentas superiores, o bien por aquellos que destinan una parte del capital económico a capital social, político, cultural o simbólico, se decantan por los artículos de mayor calidad y precio. Las dotes de las hijas de los labradores con mayores niveles de renta apostaban por la ostentación, mientras que las correspondientes al grupo de los comerciantes y los profesionales liberales eran las primeras en incorporar las innovaciones, tanto en las prendas, como en la variedad de tejidos, recurriendo incluso a las fibras de importación, como hemos indicado con anterioridad.

49. En la fabricación de estos tejidos no se utilizaba la seda de primera calidad. 
LUIS MIGUEL ROSADO CALATAYUD

LA EVOLUCIÓN DE LAS PAUTAS DE CONSUMO DE LAS FAMILIAS VALENCIANAS EN EL SIGLO XVIII

\begin{tabular}{|c|c|c|c|c|c|}
\hline \multicolumn{2}{|r|}{ CONCEPTOS } & $1700-1725$ & $1726-1750$ & 1751-1775 & $1776-1800$ \\
\hline \multirow{5}{*}{ 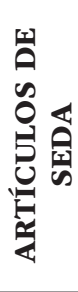 } & Valor prendas seda & 92,00 & 60,90 & 92,00 & 137,40 \\
\hline & N. ${ }^{\circ}$ prendas seda & 10,40 & 10,00 & 12,20 & 10,80 \\
\hline & Valor medio prendas seda & 8,85 & 6,09 & 7,54 & 12,72 \\
\hline & $\%$ Valor seda/total textil & $52,80 \%$ & $25,40 \%$ & $51,80 \%$ & $47,50 \%$ \\
\hline & $\begin{array}{l}\% \text { n. }{ }^{\circ} \text { prendas seda } / n .^{\circ} \\
\text { total prendas }\end{array}$ & $16,40 \%$ & $10,40 \%$ & $20,30 \%$ & $12,20 \%$ \\
\hline \multirow{5}{*}{ 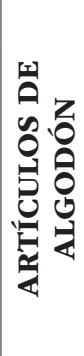 } & Valor prendas algodón & - & 2,40 & 0,90 & 24,10 \\
\hline & N. ${ }^{\circ}$ prendas algodón & - & 2,60 & 0,60 & 11,00 \\
\hline & $\begin{array}{l}\text { Valor medio prendas } \\
\text { algodón }\end{array}$ & - & 0,92 & 1,50 & 2,19 \\
\hline & $\begin{array}{l}\text { \% Valor algodón/total } \\
\text { textil }\end{array}$ & - & $1,00 \%$ & $0,50 \%$ & $8,30 \%$ \\
\hline & $\begin{array}{l}\% \text { n. }{ }^{\circ} \text { prendas algodón } / n .^{\circ} \\
\text { t. prendas }\end{array}$ & - & $2,70 \%$ & $1,00 \%$ & $12,50 \%$ \\
\hline
\end{tabular}

Cuadro 8. Artículos de seda y algodón. Área urbana. Selección de cartas dotales con valor de tasación superior. Elaboración propia. Fuente: Protocolos notariales poblaciones de la Ribera Alta y Baja y La Costera.

\begin{tabular}{|c|c|c|c|c|c|}
\hline \multicolumn{2}{|r|}{ C } & 1700-1725 & 1726-1750 & 1751-1775 & 1776-1800 \\
\hline \multirow{5}{*}{ 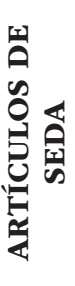 } & Valor prendas seda & 29,80 & 53,60 & 129,60 & 165,70 \\
\hline & N. ${ }^{\circ}$ prendas seda & 4,20 & 8,00 & 7,40 & 7,40 \\
\hline & Valor medio prendas seda & 7,10 & 6,70 & 17,51 & 22,39 \\
\hline & $\%$ Valor seda/total textil & $39,80 \%$ & $48,00 \%$ & $45,10 \%$ & $38,80 \%$ \\
\hline & $\begin{array}{l}\% \mathrm{n}^{\circ} \text { prendas seda } / \mathrm{n} .{ }^{\circ} \\
\text { total prendas }\end{array}$ & $10,40 \%$ & $14,10 \%$ & $8,30 \%$ & $8,10 \%$ \\
\hline \multirow{5}{*}{ 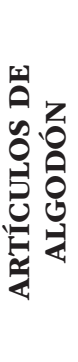 } & Valor prendas algodón & - & 4,50 & 31,00 & 78,20 \\
\hline & N. ${ }^{\circ}$ prendas algodón & - & 3,60 & 14,80 & 14,60 \\
\hline & $\begin{array}{l}\text { Valor medio prendas } \\
\text { algodón }\end{array}$ & - & 1,25 & 2,09 & 5,36 \\
\hline & $\begin{array}{l}\text { \% Valor algodón/total } \\
\text { textil }\end{array}$ & - & $4,00 \%$ & $10,80 \%$ & $18,30 \%$ \\
\hline & $\begin{array}{l}\% \mathrm{~N} .{ }^{\circ} \text { prendas algodón } / \mathrm{n} .{ }^{\circ} \\
\text { t. prendas }\end{array}$ & - & $6,40 \%$ & $16,60 \%$ & $15,90 \%$ \\
\hline
\end{tabular}

Cuadro 9. Artículos de seda y algodón. Área rural. Selección de cartas dotales con valor de tasación superior. Elaboración propia. Fuente: Protocolos notariales poblaciones de la Ribera Alta y Baja y La Costera. 
Conviene señalar que, así como en las dotes referidas a los niveles económicos más bajos, la dispersión entre los valores de inicio y final de siglo es para ambos grupos de poblaciones muy baja en términos generales ${ }^{50}$. No ocurre lo mismo con las dotes con importes de valoración más elevados, donde las oscilaciones pueden llegar a representar miles de libras $^{51}$. Podemos afirmar que la dispersión entre los niveles de tasación de las dotes se incrementa a medida que avanza el siglo. En conjunto, las dotes de las dos primeras décadas del siglo ofrecen escasas diferencias independientemente de la actividad socioprofesional de las familias, a finales del período analizado, la actividad será uno de los factores determinantes en cuanto a la diferente composición de los bienes que aparecen en la dote.

Por otra parte, a medida que las dotes alcanzan unos niveles más elevados en sus valoraciones, el peso de los artículos textiles experimenta una disminución.

En la ciudad, las dotes de la primera mitad del siglo mantienen unos valores de tasación muy superiores a los de las poblaciones del medio rural. La segunda mitad ofrece, como ya hemos tenido ocasión de comentar anteriormente, un comportamiento desigual. El período comprendido entre 1751 y 1775 supone, en relación con los períodos anteriores, un retroceso tanto en el valor como en el número de prendas. Contrariamente, los últimos años del siglo consiguen recuperar e, incluso, llegan a superar los niveles anteriores. El incremento del valor de las dotes, como hemos comentado, hace que el textil represente menos del 20\%. La mayor incidencia corresponde a las ropas de vestir, que vienen a suponer las tres cuartas partes del total; en el último cuarto de siglo llegan a significar el $80 \%$ del total, en detrimento del valor y el número de prendas del ajuar doméstico.

Dentro del apartado de la indumentaria, aquellas ropas que están confeccionadas en las distintas variedades de seda superan, a excepción del período comprendido entre 1725 y 1750 , el 50\% del total, con unos valores medios por unidad que se sitúan entre las 6 y las 12 libras.

El algodón tiene una presencia más temprana en las dotes de importes más elevados, anticipándose en 14 años al de las más bajas. A medida que avanza el siglo el algodón sigue apareciendo en unos niveles muy discretos, para acabar irrumpiendo en las dos últimas décadas en la totalidad de las dotes y alcanzar una representación del 4,2\% de los artículos de ropa de casa, aproximándose en lo que a indumentaria se refiere al número de prendas de seda, aunque su incidencia económica sea inferior, dado el menor importe unitario de este tipo de prendas.

Las dotes con niveles de valoración económica superior brindan un abanico de opciones, tanto en indumentaria como en ajuar doméstico, mucho más variado.

50. El intervalo de valoración de las dotes de menor importe oscila en el área rural entre las 22,05 y las 52,1 libras y para el área urbana entre las 22,5 y las 90,4 libras.

51. Las dotes con valores superiores se situaban, en el área rural, entre las 144,1 libras a inicio de siglo hasta las 5.770 a final de la centuria. Las correspondientes al área urbana presentaban incluso mayor dispersión, entre las 154,4 libras y las 6.818 . 
Las prendas de seda, especialmente abundantes en el caso de la ciudad de Xátiva, aunque en conjunto presentan unos importes medios ligeramente inferiores a los de las otras localidades analizadas, nos ofrecen algunas singularidades dignas de mención. Son frecuentes los guardapiés y los trajes confeccionados con tapicería, tejido de seda que por sus dibujos y colorido resultaba muy apreciado para la confección de vestidos de señora. Algo parecido podemos decir del espolín, que sobre el anterior ofrecía un colorido todavía mayor, y que además se veía enriquecido con brocados de plata y oro. El valor de tasación de alguna de estas piezas podía llegar a alcanzar las 80 libras $^{52}$. Junto a lo anterior, en las dos últimas décadas del siglo, las dotes contienen prendas de valor muy inferior. Se trata, como ya se ha comentado, de los zagalejos confeccionados con indianas, cuyos importes de tasación no alcanzan las 10 libras, pero que por su colorido acapararon el protagonismo en los guardarropas de las jóvenes casaderas.

Finalmente, las dotes referidas al medio rural, cuyos valores de tasación se sitúan en los niveles más elevados, presentan en la primera mitad de la centuria unos comportamientos muy discretos, sobre todo si los comparamos con los niveles de tasación y el número de prendas de la segunda mitad del siglo, cuyo crecimiento podemos calificarlo de exponencial. El peso del textil sobre el valor total de las dotes decrece progresivamente, a pesar de que, de modo inverso, se produce un incremento del total de artículos. Indumentaria y ajuar doméstico, en lo que a valoraciones se refiere, mantienen respectivamente unos coeficientes del $60 \%$ y el $40 \%$, frente al $70 \%$ y $30 \%$ de la ciudad. Este equilibrio se rompe en el último cuarto de siglo, en que ambos porcentajes se aproximan al 50\%.

En conjunto las ropas de seda tienen una representación menor que en el área urbana, manteniéndose en torno al 40\% del total textil, en lo que al valor de tasación se refiere. El número de prendas de indumentaria que tiene como base el tejido de seda alcanza su mayor representación entre 1726 y 1750 , con el 42,5\%, para descender en los períodos siguientes. El crecimiento que experimentan los productos textiles en la última mitad del setecientos declina por otras fibras, en especial por el algodón.

La presencia de tejidos de algodón en las dotes referidas a las poblaciones del medio rural resulta en la primera mitad del siglo inferior al 4\%. Sin embargo, en la totalidad de dotes constituidas entre 1751 y 1775, y con un número importante de prendas, encontramos artículos confeccionados con alguna de las variedades de esta fibra, lo que llega a representar un $13,2 \%$ para la ropa de casa y un $26,5 \%$ para el vestido, aunque su valor económico se sitúe por debajo de estos coeficientes. En el último cuarto de siglo el consumo del algodón, iniciado en las décadas inmediatamente anteriores, se consolida, tanto para la indumentaria como para el ajuar doméstico, situándose en ambos casos por encima de la seda en número de

52. ARV. Protocolos de Marcos Aparicio Jr., Sig. 12.476, año 1796, fols. 144v.-149r. 
prendas y consiguiendo que su peso económico en las dotes llegue a superar el $18 \%$.

En estas poblaciones, las dotes con niveles de valoración económica superior ofrecen, además de un elevado volumen de prendas, especialmente en lo que a la ropa de casa se refiere, unos importes medios altos debido a la composición cualitativa de los diferentes artículos. Se incrementa el número de prendas y además hacen su aparición nuevos tipos de vestidos, ausentes en las dotes de menor importe, casacas, basquiñas, pero sobre todo los vestidos y los trajes, que pueden superar en valor unitario las 75 libras. Algo parecido ocurre con el ajuar doméstico, en el que los juegos de "cobertor, antecama y tapete», de damasco, guarnecidos con franja y generalmente de color carmesí, podían llegar a alcanzar un valor de 50 libras $^{53}$. No obstante, en este tipo de complementos destinado a un uso privado concurre una circunstancia que les confiere una dimensión pública y los sitúa al nivel de la indumentaria. En los acontecimientos festivo-religiosos, en particular las procesiones, para engalanar las calles se recurría a la colocación de colchas en las fachadas, balcones y ventanas, cuyo objetivo era su exhibición, más que la funcionalidad del artículo.

\section{A MODO DE CONCLUSIÓN}

La amplia variedad de bienes materiales que nos muestran las escrituras de dote, la evolución del tipo de prendas, así como el número de las mismas, y la calidad de los tejidos utilizados en el vestido personal y en la ropa de casa nos han permitido apreciar cambios de actitud respecto al consumo, así como establecer una diferenciación de las pautas de conducta de las familias en ambos tipos de comunidades.

No obstante, más que de un proceso de cambios profundos y de una sucesión rápida de las transformaciones en las pautas de consumo familiar, las investigaciones más recientes apuntan en la dirección de un proceso de evolución lento y acumulativo, difícilmente calificable de revolucionario. Estas mutaciones mostraron sus primeras señales en las áreas más desarrolladas de Europa en el siglo XVII, aunque con progreso muy desigual como consecuencia del avance de la industrialización, el principal motor del cambio.

En el área central del territorio valenciano las innovaciones adoptadas en materia agrícola dieron sus principales frutos a lo largo del siglo XVIII. Las economías domésticas -derivadas de una mayor participación en la actividad productiva de la

53. En la escritura de dote y arras que constituyen los esposos Mariano Artal, labrador hacendado, y Rosa María Baldoví, a favor de su hija Josefa aparece un «vestido nuevo de seda y saya bordado", valorado en 75. Así como un juego de "cobertor, antecama y sobremesa, en damasco, color carmesí...” valorado en 50 libras. ARV. Protocolos Notariales de Marcos Aparicio Jr., Sig. 12.477, Año 1797, fols. 237v.-242r. 
práctica totalidad de sus miembros, como consecuencia de las mejores oportunidades que ofrecía la agricultura comercial-, experimentaron una evolución positiva. La adopción de estas prácticas vino a significar variaciones en la estructura de la propiedad, así como cambios de comportamiento de la sociedad local. Junto a las familias de pequeños propietarios y artesanos, que habían mejorado su posición económica, tanto en el medio rural como en el urbano, hicieron aparición un reducido grupo de labradores hacendados, a los que habría que añadir a aquellos vecinos dedicados al comercio y a diferentes oficios y profesiones, que habían protagonizado un ascenso económico importante con la nueva situación, y que deseaban también conseguir el reconocimiento social. Querían afirmar ante el vecindario el nuevo estatus alcanzado. Para ello nada mejor que la imagen exterior. El vestido era el que representaba la mejor forma de expresión. La indumentaria debía ser capaz de materializar la pretendida promoción social del sujeto que lo poseía o de la familia que lo entregaba como donación. La riqueza del tejido con la que había sido confeccionado, la exclusividad o la singularidad del modelo suponían unas referencias claras del coste del bien material, pero, al mismo tiempo, lo que se pretendía era precisamente dejar constancia de este hecho. La posesión de determinadas prendas constituía un importante argumento dentro de lo que podíamos denominar la lucha simbólica entre el ser y el parecer. La trasformación en las pautas de consumo adquirió su máxima significación en el vestido de uso personal.

A pesar de que completar el guardarropa de las novias podía comportar un importante esfuerzo económico -incluso en algunos casos la necesidad de recurrir al endeudamiento-, la trascendencia social que llegaron a representar las dotes significaba mucho más que la dedicación de un capital económico. Para la adquisición de unas basquiñas o de un jubón de seda, se podía llegar a destinar una cantidad equivalente al jornal anual de un obrero. Pero hay que tener en cuenta que la constitución de una dote no tenía la consideración de un gasto, para algunas familias podía llegar a representar la inversión más rentable que realizaban en sus vidas. Por este motivo no dudaban en recurrir a lo que fuera necesario, porque lo importante era conseguir la celebración de una buena boda. El contrato matrimonial, en el Antiguo Régimen, guardaba más relación con lo mercantil que con lo afectivo. Pero, además, en la asignación de las cantidades destinadas a dotar a las hijas concurrían otras muchas circunstancias. Como hemos tenido ocasión de comprobar, intervenían una multiplicidad de factores de orden social, económico, cultural, e incluso político, que determinaban la necesidad de adoptar unos comportamientos concretos en un tiempo determinado. Para las familias mejor situadas económicamente destinar mayores cantidades al vestido para seguir los dictados de la moda no suponía ninguna dificultad. Aquellas que disponían de recursos más limitados, siempre podían acudir al mercado de ocasión y tratar de actualizar las prendas usadas, como nos muestra la documentación.

De manera progresiva en la Valencia del siglo XVIII asistimos a un despegue importante de los niveles de consumo. Aparecen nuevos planteamientos en materia de vestir, en los que el mercado no es ajeno. La llegada de nuevas fibras y la necesidad 
de seguir la moda animaron el comercio. Oferta y demanda quedaban entrelazadas. A partir de la segunda mitad del Setecientos se produce una «democratización» de las formas de vestir, debido la proliferación de los tejidos de algodón. Esta nueva fibra, gracias a las técnicas de estampación y a su reducido precio, no solo desplazó al lino y el cáñamo en la ropa de casa, sino que pasó a ser adoptada de modo preferente en las prendas de vestir. La utilización del algodón generó una auténtica revolución en el consumo. Incluso la lana y la seda, que se utilizaban preferentemente en los trajes más suntuosos, también se vieron relegadas.

La transmisión de las novedades en materia de indumentaria seguiría distintos cauces. Los contactos cada vez más frecuentes del medio rural, debido a la orientación de la agricultura al mercado y la imitación de los comportamientos urbanos, derivados de las nuevas prácticas de sociabilidad, obligaban a una mayor preocupación por el vestido. Como resultado de lo anterior, nos hallamos ante una nueva cultura de consumo, donde gastar es un imperativo categórico. El vestido se convirtió en un identificador de clase. En el proceso de difusión de la circulación de las nuevas modas y los cambios incorporados en las prácticas de consumo adoptados por las familias valencianas, debemos señalar, entre otros factores, el incremento de la actividad comercial, por medio de vendedores ambulantes, o la presencia de tiendas estables, así como la incidencia de la prensa escrita, que comenzaba a actuar como medio de comunicación. Pero la mayor influencia respondía a los comportamientos miméticos, que, lejos de seguir una trasmisión vertical -cuyo protagonismo hubiera correspondido a las clases altas que componían la élite social-, se produjo en forma de ondas de avance, en cuyo epicentro debemos situar a aquellos sujetos con una mayor proyección pública, bien porque ejercían profesiones liberales o bien porque desempeñaban actividades comerciales, incluidos algunos de los componentes de la élite política, por lo que se refiere a la ciudad de Xàtiva. En todos los casos, se trataba de individuos pertenecientes a las clases medias y medias-altas. Los nuevos hábitos adquisitivos seguidos por ellos acabarían llegando a todas las categorías sociales, y se propagarían de manera progresiva por los diferentes rincones de la geografía valenciana. 